\section{Pulmonary hypertension due to chronic hypoxia}

\author{
Treat the lung not the pressure
}

Pulmonary vasoconstriction in response to hypoxia is a basic reflex that occurs in all mammals studied. It has long been thought to have two main physiological functions. In the fetus it is responsible for closing off the pulmonary circulation to prevent blood from shunting through the unventilated lung. After birth it ensures that perfusion is constantly matched to ventilation. The problem comes when the lung is faced with global hypoxia due either to high altitude or to chronic hypoxic lung disease. Then the reflex seems malign and causes pulmonary hypertension. Not surprisingly, hypoxic vasconstriction is virtually absent in those animals that live constantly at high altitude. Bar headed geese, for example, fly over the Himalayas to nest in Tibet. These birds and also mammals that live at high altitude seem to suffer very little from their inability to control the flow of blood to the underventilated lung - so is the reflex of any benefit to adult animals or man?

Patients with chronic hypoxic lung disease (usually chronic bronchitis and emphysema but also chronic asthma and restrictive diseases such as fibrosing alveolitis and kyphoscoliosis) are all at risk of pulmonary hypertension, and its development is associated with a poor prognosis.' Some authors have claimed that the pulmonary hypertension in these patients is coincidental to their poor prognosis and poor exercise tolerance rather than their cause. They base this assertion on the observation that the resting pulmonary artery pressure is often not high in patients with severe lung disease. A mean pressure of only $30 \mathrm{~mm} \mathrm{Hg}$ is typical-whereas in primary pulmonary hypertension it may often reach systemic values. In such patients, however, the pulmonary pressure may rise much higher on exercise, owing to the low compliance of the constricted pulmonary circulation, or at night, owing to worsening hypoxia. Furthermore, the low oxygen content of the arterial blood means that adequate oxygen delivery to the tissues depends on a high cardiac output, and these patients are often unable to raise their cardiac outputs further on exercise because of the increased afterload. ${ }^{2}$

So, if pulmonary hypertension in chronic hypoxic lung disease is important, how can we recognise it, and how should we treat it? Typically the patient with secondary pulmonary hypertension will complain of current or past episodes of fluid retention and will have fixed airflow obstruction (forced expiratory volume in one second less than 1.5 litres), hypoxaemia (arterial pressure of oxygen below $8 \mathrm{kPa}$ ), and hypercapnia (arterial carbon dioxide pressure over $6 \mathrm{kPa}$ ). The chest radiograph may show an enlarged pulmonary artery and the electrocardiogram may show $\mathrm{P}$ pulmonale, right axis deviation, and dominant $\mathrm{R}$ waves in lead V1. In the end the diagnosis depends on the findings at right heart catheterisation, and this should be available in any specialist respiratory unit. In the future new techniques of Doppler echocardiography should provide the same information non-invasively, but at present adequate Doppler signals are seen in only about a third of patients because of interference by the overlying lung (unpublished data).

The treatment of secondary pulmonary hypertension has centred on the use of vasodilators including $\beta_{2}$ agonists, hydralazine, isosorbide, calcium antagonists, and angiotensin converting enzyme (ACE) inhibitors. ${ }^{3-9}$ Of the vasodilators the ACE inhibitors might be expected to be the most effective because they have the potential to improve two aspects of the disorder-namely, the pulmonary hypertension and the fluid retention, which is thought to be due to the effects of hypoxaemia and hypercapnia on the kidney. ${ }^{10}$ The problem with all the vasodilators (other than oxygen) is that they are non-selective and cause unwanted systemic vasodilatation, which limits their use. There are hopes that selective vasodilators will be developed; until they are, no further studies of vasodilators need be done. Their limited value implies that, at present, treatment should concentrate on maximising lung function and improving oxygenation, if necessary by the use of domiciliary oxygen.

All patients with chronic hypoxic lung disease and an episode of fluid retention should be referred to a specialist unit. There they should have lung function studies including assessment of the extent of the reversal of the airflow obstruction by $\beta_{2}$ agonists, anticholinergics, and steroids and measurement of arterial blood gas tensions. If appropriate these patients should also be assessed for suitability for domiciliary treatment with oxygen, should undergo measurement of pulmonary haemodynamics, and have sleep studies to rule out nocturnal deterioration of hypoxaemia. Remarkably, often patients' pulmonary haemodynamics and exercise tolerance will be improved by these measures.

Senior Registrar in Respiratory Medicine,

ANDREW PEACOCK

Southampton General Hospital,

Southampton SO9 4XY

Weitzenblum E, Hirth C, Ducolone A, Mirhom R, Rasaholinianahary J, Ehrhart M. Prognostic value of pulmonary artery pressure in chronic obstructive lung disease. Thorax 1981;36:752-8. value of pulmonary artery pressure in chronic obstructive lung discase. Thorax $1981 ; 36: 752-8$.
Morrison DA. Pulmonary hypertension in chronic obstructive pulmonary disease: the right ventricular hypothesis. Chest 1987;92:387-9.

3 Danahy DT, Tobis JM, Aronow WS, Chetty K, Glauser F. Effects of isosorbide dinitrate on pulmonary hypertension in chronic obstructive pulmonary disease. Clin Pharmacol the 1979;25:541-8.

4 Peacock AJ, Busst C, Dawkins K, Denison DM. Response of the pulmonary circulation to oral pirbuterol in chronic airflow obstruction. Br.Med $\mathcal{F}$ 1983;287:1178-80.

5 Macnee W, Wathen CG, Hannan WJ, Flenley DC, Muir AL. Effects of pirbuterol and sodium nitroprusside on pulmonary haemodynamics in hypoxic cor pulmonale. Br Med $\mathcal{F}$ 1983;287 $1169-72$.

6 Keller CA, Shepard JW Jr, Chun DS, Dolan GF, Vasquez P, Minh V-D. Effects of hydralazine on haemodynamics, ventilation, and gas exchange in patients with chronic obstructive pulmonary disease and pulmonary hypertension. Am Rev Respir Dis 1984;130:606-11.

7 Kennedy TP, Michael JR, Chun-Kang H. Nifedipine inhibits hypoxic pulmonary vasoconstriction during rest and exercise in patients with chronic obstructive pulmonary disease. Am Rev Respir Dis 1984;129:544-51.

8 Muramoto A, Caldwell J, Albert RK, Lakshminaravan S, Butler J. Nifedipine dilates the pulmonary vasculature without producing symptomatic systemic hypotension in upright restin and exercising patients with pulmonary hypertension secondary to chronic obstructive pulmonary disease. Am Rev Respir Dis 1985;132:963-6.

pulmonary disease. Am Rev Respir Dis 1985;132:963-6.
9 Peacock A, Matthews A. The effect of captopril on pulmonary haemodynamics and lung function in patients with chronic airflow obstruction. Thorax 1986;41:225.

10 Oliver RM, Peacock AJ, Fleming JS, Waller D. The renal and pulmonary effects of captopril in patients with hypoxic lung disease. Thorax 1989;44:513-5.

\section{Varicose veins}

\section{An increasing burden for the NHS}

Varicose veins are a major and increasing burden to the health service. Over 50000 patients were admitted to hospital for treatment in 1987-8 - almost twice as many as in $1975 .{ }^{2}$ Many hospitals have huge waiting lists for operations on veins, and some surgeons will not see new patients with this complaint. A low level of interest by doctors has been suggested as the cause of this state of affairs. ${ }^{3}$ The primary causes, however, are the high prevalence of varicose veins ${ }^{+5}$ and the substantial time required for treatment of a condition that is not a serious threat to health.

The term varicose veins includes anything from minor cosmetic blemishes to important venous hypertension with 